\title{
Outcome of Teenage Pregnancy at a Tertiary Hospital in Abakaliki Southeast Nigeria
}

\author{
Robinson Chukwudi Onoh, Paul Olisaemeka Ezeonu, Bonaventure Okechukwu Anozie, Chidi Ochu Uzoma Esike, \\ Johnson A Obuna, Chukwuma Egbuji, Uzoma Maryrose Agwu, Joseph Agboeze, Ibekwe Perpertus Chukwudi \\ Department of Obstetrics and Gynecology, Federal Teaching Hospital Abakaliki, Abakaliki, Ebonyi State, Nigeria
}

\section{A B S T R A C T}

Background: Teenage pregnancy is a high risk pregnancy associated with obstetric, fetal, neonatal and psycho-social complications. These complications are worsened by poverty, ignorance and lack of special care during pregnancy. Aim: The objective of the following study is to determine the obstetric and neonatal outcome of teenage pregnancy. Materials and Methods: A retrospective case control study was carried out over a 6 years period, 2006-2011. All teenage pregnancies (aged 13-19 years) at Federal Medical Center Abakaliki, Ebonyi were taken as cases. Pregnancy deliveries from mothers aged 20 to 29 that met the inclusion criteria were selected as controls. A total of 137 teenage pregnancies were analyzed and compared with 948 controls. Statistical analysis was performed using 2008 Epi-info statistical software version 3.5.1 (Atlanta, Georgia, USA). Results: The incidence of teenage deliveries over the period of the study was (137/8020) $2.25 \%$. Single mothers were commoner (40.9\% [56/137] vs. 3.1\% [29/948], $P<0.01)$ among the teenagers. Low educational status was more common among teenage mothers $(P<0.01)$. Unbooked pregnancies were significantly common among teenage mothers (23.4\% [32/137] vs. 12.3\% [117/948], $P<0.01)$. Anemia in pregnancy (18.1\% [41/226] vs. 11.2\% [65/579], $P=0.01)$, human immunodeficiency virus (HIV) in pregnancy (4.9\% [11/226] vs. 1.7\% [10/579], $P=0.01)$ and malaria in pregnancy $(26.1 \%$ [59/226] vs. $12.4 \%[72 / 579], P<0.01)$ were significantly common in teenage pregnancies than the control. Teenage mother had significantly increased cesarean deliveries (23\% [31/137] vs. 14.8\% [140/948], $P<0.02)$, male deliveries (64.3\% [90/140] vs. 52.1\% [502/963], $P<0.03)$ and low birth weight (19.3\% [27/140] vs. 12.7\% [122/963], $P<0.03)$. Fetal loss $(22.1 \%[31 / 140]$ vs. 3.3\% [32/963] $P<0.01)$ and birth asphyxia (19.3\% [27/140] vs. 6.8\% [65/963], $P<0.01)$ were significantly common among teen mothers in the 1 st min American Pediatric Gross Assessment Records score. Conclusion: Teenage pregnancies were associated with a significantly higher risk of anemia in pregnancy, HIV in pregnancy, malaria in pregnancy, cesarean deliveries and poor fetal outcome. Health education, women enlightenment and empowerment will be essential in reducing the problems of teenage pregnancy.

KEY WORDS: Abakaliki, outcome, teenage pregnancy, tertiary hospital

\section{INTRODUCTION}

Teenage pregnancy dates back to the early centuries and a famous teenage pregnancy in history was Mary, mother of Jesus who is generally believed to have given birth to Jesus at the age of 13 years. ${ }^{[1]}$ Teenage pregnancy globally is discouraged today because it has been shown to be associated with an increase obstetric

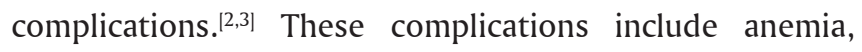
preterm labor, prematurity, low birth weight, operative vaginal delivery, cesarean section, pregnancy induced

\begin{tabular}{|l|l|}
\hline \multicolumn{2}{|c|}{ Access this article online } \\
\hline Quick Response Code & Website: \\
& www.jbcrs.org \\
\cline { 2 - 2 } & DOI: \\
& $* * *$ \\
\hline
\end{tabular}

hypertension, eclampsia, puerperal sepsis, cephalopelvic disproportion and psycho-social problems of unwanted pregnancy. ${ }^{[2-5]}$ The predisposing determinants of the above named complications among teenage pregnancies include poverty, ignorance, lack of specialized care during pregnancy. These increase the risks of a teenager dyeing from pregnancy. United Nations has estimated that about 53,000 women in Nigeria die annually of pregnancy related illnesses and teenage pregnancy contributes significantly to these deaths.

The problem of teenage pregnancy is worrisome especially in developing countries where the incidence is on the increase. This increase has been attributed to early age of sexual maturation with decreasing age of menarche, lack

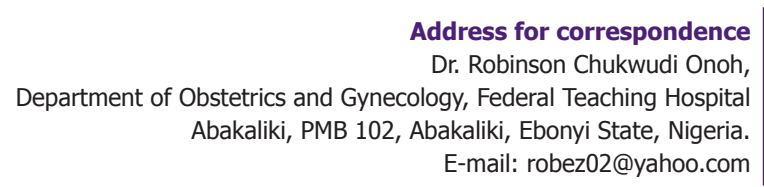

Address for correspondence gy, Federal Teaching Hospital E-mail: robez02@yahoo.com 
of parental guidance, lack of education on contraceptives method, peer pressures, early age at coitarche, loss of cultural norms and values as well as increased fertility among teenagers. ${ }^{[6-8]}$ Varying incidence has been recorded in Nigeria with a range of $3.7-21.9 \%$ of all pregnancies. ${ }^{[3,4,9,10]}$

However, the true incidence may actually be higher than the above findings as many teen pregnancies are terminated and never recorded..$^{[9]}$

Several studies have been carried out on teenage pregnancy in Nigeria and sub-Saharan African but no study has been carried out at Federal Medical Center (FMC) on teenage pregnancy. There is also paucity of recent studies on the Southeast Nigeria on teenage pregnancy. We therefore aim to evaluate the maternal and fetal outcome of teenage pregnancies in a tertiary hospital over a 6 year period.

\section{MATERIALS AND METHODS}

This was a retrospective case controlled study of teenage pregnancies and other pregnancies within the age range of 20-29 years conducted at FMC Abakaliki, Ebonyi State over a period of 6 years from January 2005 to December 2010. FMC is a tertiary institution located in the capital city of Ebonyi State and receives referral from all parts of the state and neighboring state of Benue, Enugu, Cross River and Abia as well as any part of the country, Nigeria.

Teenage pregnancy in the study was defined as pregnancies occurring between the maternal ages of 13-19 years at deliveries. All cases of teenage pregnancies that presented at the FMC were included in the study. They were compared with pregnancies within 20-29 years within the study period. Pregnancies between 13 and 19 years were taken as the case while those between 20 and 29 were taken as control.

Pregnancies that were not carried to the age of viability of 28 weeks gestational age and those that were not delivered at the hospital were excluded. Furthermore, women who had a previous cesarean section previous, uterine surgeries, those that had obvious indications for cesarean section such as cephalopelvic disproportion, repair of genital fistula were excluded in the control.

Permission was obtained from the ethics and research committee of the hospital to embark on this study. The case notes of the selected patients were retrieved and analyzed. The variables analyzed include age, marital status, booking status, complication in pregnancy, mode of delivery and outcome of pregnancy. Patients who were first seen in labor were regarded as unbooked whether there were referred from another hospital or not. Preterm deliveries were taken as deliveries that occurred at less than 37 completed weeks and low birth weight were babies that weighted less than $2.5 \mathrm{~kg}$.

Data was analyzed using the Epi-info software package version 3.5.1 2008, (CDC, Atlanta, Georgia, USA). Chi-square analysis was carried out to determine the associations and level of significance was set at $P<0.05$. Fischer's exact test was preferred when any of the expected cell unit is less than 5 and was used to determine the level of associations.

\section{RESULTS}

There were a total of 8020 deliveries within the study period and there were 137 teenage deliveries. This gives a teenage pregnancy rate of 22.5/1000 deliveries. The mean age of teenage pregnancy in this study was 17.9 (1.27) years with a range of 13-19 years. Most teen mothers in this study 61/137 (44.5\%) were 19 years old. Age of mothers in this study maintained a progressively ascending trend from 13 years reaching the highest age of occurrence of teenage pregnancy at 19 years. These findings were shown in Figure 1.

Socio-demographic variables and its relations to teenage pregnancies were illustrated in Table 1 . Single mothers were significantly higher in teenage pregnancies when compared with the control with rate of $40.9 \%(56 / 137)$ to $3.1 \%$ (29/948) and $P$ value of 0.01 . Low educational level (no formal education [35/137] 25.5\% vs. [34/948] 3.6\%), (primary education [37/137] $27.0 \%$ vs. [48/948] 5.1\%), (secondary

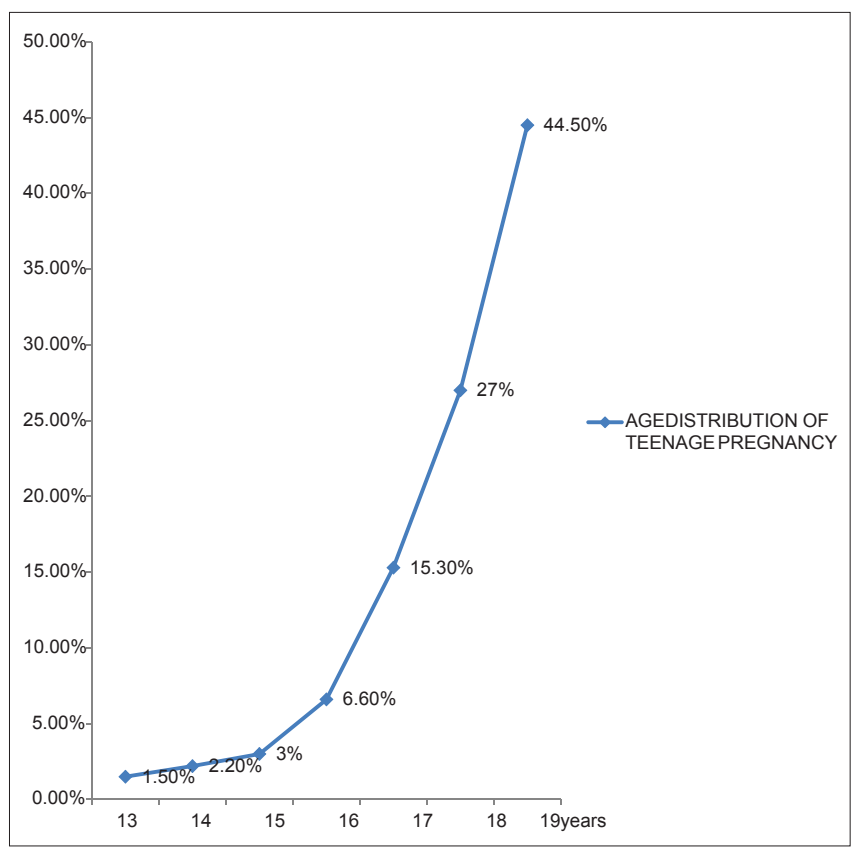

Figure 1: Frequency of age distribution of teenage pregnancy 
education [52/137] 40.0\%vs. [109/948] 11.5\%) was significantly higher in teen pregnancies when compared with the control with $P$ values of 0.01 while high educational level (tertiary education) was significantly lower among the teenage mothers $(9.5 \%$ [13/137] vs. $79.9 \%$ [757/948], $P=0.01)$. Unbooked pregnancies were significantly higher in teenage pregnancy with percentage of $23.4(32 / 137)$ to $12.3(117 / 948)$ among the control with $P$ value of 0.01 . Tribe and religion showed no significant association with teenage pregnancy.

The complications in pregnancy among the teen mothers were compared with the control in Table 2 . The complications that were significantly higher among teenage pregnancy when compared with the control include anemia in pregnancy taken as hemoglobin concentration $<10 \mathrm{~g} / \mathrm{dl}(18.1 \%$ [41/226] vs. $11.2 \%[65 / 579] P=0.01$ ), human immunodeficiency virus (HIV) infection in pregnancy $(4.9 \%[11 / 226]$ vs. $1.7 \%[10 / 579], P=0.01)$ and malaria in pregnancy $(26.1 \%$ [59/226] vs. $12.4 \%[72 / 579]$ $P<0.01)$. Preterm deliveries (12.0\% [27/226] vs. $21.1 \%[122 / 579]$ $P=0.003)$ and postpartum hemorrhage $(6.2 \%$ [14/226] vs. $15.9 \%[92 / 579] P<0.01)$ were significantly commoner in control than in teenage pregnancies. There was no significant association between teenage pregnancy and the control group with regards to bleeding per vagina in early pregnancy (before the age of viability), diabetes in pregnancy, pre-eclampsia, eclampsia, ruptured uterus, antepartum hemorrhage, retained placenta and twin gestation $(P \geq 0.05)$. However, pre-eclampsia $(6.6 \%$ [15/226] vs. $3.8 \%$ [22/579], $P=0.08)$, eclampsia $(3.5 \%[8 / 226]$ vs. $3.3 \%[19 / 579], P=0.86)$ and antepartum hemorrhage $(2.2 \%$ [5/226] vs. $2.1 \%[12 / 579]$, $P=1.00$ ) were more common in teenage pregnancies than the control but did not attain statistical significance.

Table 3 shows fetal presentation and mode of delivery in teenage pregnancies compared with deliveries among women aged 20-29 years. There was no significant difference in the fetal presentation among teen pregnancies when compared with the control $(P \geq 0.05)$. Caesarean section was significantly a more common mode of delivery among the teenage pregnancies than the control $(23.0 \%$ [31/137] vs. $14.8 \%[140 / 948] P=0.02)$. The other modes of delivery did not attain statistical significance $(P>0.05)$ and the most common mode of delivery seen in this study was spontaneous vertex delivery for the teen mothers $103 / 137(76.3 \%)$ and the control 781/948 (82.4\%).

The sex, weight and outcome of babies after delivery in the teenage pregnancies and the control were shown in Table 4. Most of the babies delivered were males and this was significantly higher in teenage pregnancies $90(64.3 \%)$ than the control $502(52.1 \%)$ with $P=0.01$. Low birth weight $(<2.5 \mathrm{~kg})$ was also a significantly common finding among teen deliveries (19.3\% vs. $12.7 \%$ $P=0.03)$. Most of the deliveries were of normal weight in both teenage pregnancies $112(80.0 \%)$ and the control $822(85.4 \%)$ while macrosomic babies had the lowest number of deliveries $(1[0.7 \%]$ vs. $19[2.0 \%])$ and both did not attain statistical significance with $P$ values of 0.1 and 0.48 respectively. Fetal death was a significantly common finding among the teen mothers when compared with the control $(22.1 \%$ vs. $3.3 \% P=0.01)$.

Table 5 shows the $1^{\text {st }}$ and $5^{\text {th }}$ min American Pediatric Gross Assessment Records (APGAR) score for the teen deliveries and the control. Birth asphyxia and still birth were significantly more common among the teen deliveries than the control in the $1^{\text {st }}$ min APGAR score $(12.9 \%$ vs. $3.2 \% P<0.01)$ and $(19.3 \%$ vs. $6.8 \% P<0.01)$ respectively. Good APGAR score was a significantly more common finding among the control $(67.9 \%$ vs. $90.0 \% P<0.01)$ and this constitutes the majority of the deliveries in this study. In the $5^{\text {th }}$ min APGAR score fetal death was

\begin{tabular}{|c|c|c|c|c|}
\hline \multicolumn{5}{|c|}{$\begin{array}{r}\text { Table 1: Socio-demographic variables and i } \\
\text { teenage pregnancy }\end{array}$} \\
\hline Variables & $\begin{array}{c}13-19 \text { years } \\
n=137(\%)\end{array}$ & $\begin{array}{c}\text { 20-29 years } \\
n=948(\%)\end{array}$ & $\chi^{2}$ & $P$ value \\
\hline \multicolumn{5}{|l|}{ Marital status } \\
\hline Single & $56(40.9)$ & $29(3.1)$ & 237.09 & 0.01 \\
\hline Married & $81(59.1)$ & $919(97.0)$ & & \\
\hline \multicolumn{5}{|l|}{ Religion } \\
\hline Christian & $132(96.4)$ & $936(98.7)$ & 3.0 & 0.08 \\
\hline Muslim & $5(3.6)$ & $12(1.3)$ & & \\
\hline \multicolumn{5}{|l|}{ Educational level } \\
\hline No formal education & $35(25 \cdot 5)$ & $34(3.6)$ & 304.33 & $<0.01$ \\
\hline Primary & $37(27.0)$ & $48(5.1)$ & & \\
\hline Secondary & $52(40.0)$ & $109(11.5)$ & & \\
\hline Tertiary & $13(9.5)$ & $757(79.9)$ & & \\
\hline \multicolumn{5}{|l|}{ Tribe } \\
\hline Ibo & $133(97.1)$ & $911(96.1)$ & 4.98 & 0.20 \\
\hline Hausa & $2(1.45)$ & $4(0.4)$ & & \\
\hline Yoruba & 0 & $10(1.1)$ & & \\
\hline Others & $2(1.45)$ & $23(2.4)$ & & \\
\hline \multicolumn{5}{|l|}{ Booking status } \\
\hline Booked & $105(76.6)$ & $831(87.7)$ & 12.26 & 0.01 \\
\hline Unbooked & $32(23.4)$ & $117(12.3)$ & & \\
\hline
\end{tabular}

\begin{tabular}{|c|c|c|c|c|}
\hline Variables & $\begin{array}{c}\text { 13-19 years } \\
n=226(\%)\end{array}$ & $\begin{array}{c}20-29 \text { years } \\
n=579(\%)\end{array}$ & $\chi^{2}$ & $P$ value \\
\hline Bleeding in pregnancy before 28 weeks & $6(2.7)$ & $26(4.5)$ & 1.44 & 0.23 \\
\hline Anemia in pregnancy & $41(18.1)$ & $65(11.2)$ & 6.799 & 0.01 \\
\hline Pre-eclampsia & $15(6.6)$ & $22(3.8)$ & 2.99 & 0.08 \\
\hline HIV in pregnancy & $11(4.9)$ & $10(1.7)$ & 6.31 & 0.01 \\
\hline Eclampsia & $8(3.5)$ & $19(3.3)$ & 0.03 & 0.86 \\
\hline Malaria in pregnancy & $59(26.1)$ & $72(12.4)$ & 22.30 & $<0.01$ \\
\hline Diabetic in pregnancy & $3(1.3)$ & $13(2.3)$ & 0.70 & 0.58 \\
\hline Intrauterine fetal death & $8(3.5)$ & $28(4.8)$ & 0.64 & 0.42 \\
\hline Preterm delivery & $27(12.0)$ & $122(21.1)$ & 8.97 & $<0.01$ \\
\hline Postpartum hemorrhage & $14(6.2)$ & $92(15.9)$ & 13.36 & $<0.01$ \\
\hline Premature rupture of membranes & $15(6.6)$ & $40(6.9)$ & 0.02 & 0.89 \\
\hline Ruptured uterus & $1(0.4)$ & $8(1.4)$ & 0.65 & 0.46 \\
\hline Antepartum hemorrhage & $5(2.2)$ & $12(2.1)$ & 0.00 & 1.00 \\
\hline Retained placenta & $10(4.4)$ & $35(6.0)$ & 0.81 & 0.37 \\
\hline Twin gestational & $3(1.3)$ & $15(2.6)$ & 1.19 & 0.43 \\
\hline
\end{tabular}

Multiple entries allowed. HIV - Human immunodeficiency virus 


\begin{tabular}{|c|c|c|c|c|}
\hline Variables & $\begin{array}{c}\text { Teenage pregnancy } \\
\quad \mathrm{N}=137(\%)\end{array}$ & $\begin{array}{c}\begin{array}{c}\text { Control } \\
N=948(\%)\end{array} \\
\end{array}$ & $x^{2}$ & $P$ value \\
\hline $\begin{array}{l}\text { Presentation } \\
\text { Cephalic } \\
\text { Breech } \\
\text { Transverse }\end{array}$ & $\begin{array}{c}131(95.6) \\
6(4.4) \\
0\end{array}$ & $\begin{array}{c}896(94.5) \\
26(2.7) \\
2(0.2)\end{array}$ & 1.420 & 0.46 \\
\hline $\begin{array}{l}\text { Mode of delivery } \\
\text { Spontaneous vertex delivery } \\
\text { Cesarean section } \\
\text { Vacuum extraction }\end{array}$ & $\begin{array}{c}103(76.3) \\
31(23.0) \\
1(0.7) \\
\end{array}$ & $\begin{array}{c}781(82.4) \\
140(14.8) \\
27(2.8) \\
\end{array}$ & 7.03 & 0.02 \\
\hline
\end{tabular}

\begin{tabular}{|c|c|c|c|c|}
\hline Variables & $\begin{array}{c}\text { Teenage deliveries } \\
n=140(\%)\end{array}$ & $\begin{array}{c}\text { Control } \\
n=963(\%)\end{array}$ & $x^{2}$ & $P$ value \\
\hline \multicolumn{5}{|c|}{ Sex of babies delivered } \\
\hline Male & $90(64.3)$ & $502(52.1)$ & 7.27 & 0.01 \\
\hline \multirow{2}{*}{\multicolumn{5}{|c|}{ Weight of babies }} \\
\hline & & & & \\
\hline$<2.5$ & $27(19.3)$ & $122(12.7)$ & 4.58 & 0.03 \\
\hline $2.5-3.9$ & $112(80.0)$ & $822(85.4)$ & 2.71 & 0.10 \\
\hline$\geq 4.0$ & $1(0.7)$ & $19(2.0)$ & 0.50 & 0.48 \\
\hline \multicolumn{5}{|c|}{ Fetal outcome } \\
\hline Alive & 109 (77.9) & $931(96.7)$ & 80.39 & $<0.01$ \\
\hline Dead & $31(22.1)$ & $32(3.3)$ & & \\
\hline
\end{tabular}

\begin{tabular}{l|c|c|c|c}
\hline \multicolumn{5}{c}{ Table 5: APGAR score of teenage deliveries and control } \\
\hline Variables & $\begin{array}{c}\text { Teenage deliveries } \\
\mathbf{n}=\mathbf{1 4 0}(\%)\end{array}$ & $\begin{array}{c}\text { Control } \\
\mathrm{n}=\mathbf{9 6 3}(\%)\end{array}$ & $\chi^{2}$ & P value \\
& $18(12.9)$ & $31(3.2)$ & 55.48 & $<0.01$ \\
\hline $1^{\text {st }} \min$ APGAR & $27(19.3)$ & $65(6.8)$ & & \\
0 & $95(67.9)$ & $867(90.0)$ & & \\
$<7$ & $31(22.1)$ & $32(3.3)$ & 56.59 & $<0.01$ \\
$7-10$ & $4(2.9)$ & $17(1.8)$ & & \\
$5^{\text {th }}$ min APGAR & $105(75.0)$ & $914(94.9)$ & & \\
0 & $<7$ & & & \\
$7-10$ &
\end{tabular}

significantly more common in the teen deliveries than the control $(22.1 \%$ vs. $3.4 \% P<0.01)$. Furthermore, majority of the deliveries had good APGAR score at the $5^{\text {th }}$ min with 105 (75\%) for the teen mothers and 914 (94.9\%) for the control. This also attained statistical significance with $P<0.01$.

\section{DISCUSSION}

The overall incidence of teenage pregnancy obtained in this study was $2.25 \%$ or $22.5 / 1000$ deliveries. This incidence is lower than $6.5 \%$ reported by Loto et al. at Ile-Ife Southwest of Nigeria, 5\% reported by Harrison in Zaria Northern Nigeria, ${ }^{[11]} 2.18 \%$ reported by lgwegbe and Udigwe in Nnewi Southeast Nigeria, $3.7 \%$ reported by Ogunniyi et al. at Ile-Ife Southwest Nigeria, ${ }^{[4]} 1.93 \%$ reported by Jimoh and Abdul in Ilorin Southwest Nigeria. ${ }^{[6]}$

The low incidence rate seen in this study may be because of change in the trend from early marriage to delayed marriage seen among the Ibo-community in the southeastern part of Nigeria. ${ }^{[9]}$

The inhabitants of this community are predominantly Christians and have also embraced Western education delaying marriage until post-tertiary education. Also, there may be an increase uptake of contraception among the literate group resulting in reduction of unwanted pregnancies during the pursuit of western education as well as delay in marriage. Pregnancy outside wedlock is seen as taboo in this part of the country; as such many teenagers may resort to termination of unwanted pregnancies as it may jeopardize their chances of being patronized by a promising husband. In addition, the low incidence may be because this study was carried out in a tertiary hospital where there are lots of hospital staffs and beaurocracy, which may reduce privacy and secrecy unlike in private and mission hospitals which are prominent in this part of Nigeria with reduced number of staff which may help to entrust privacy and secrecy.

The high incidence seen in Southwest and Northern part of Nigeria are attributed to early marriage which is encouraged by the socio-cultural background, as well as the Muslim faith which dominates the above regions of Nigeria. ${ }^{[9]}$ High incidence of teenage pregnancy is a common finding in India, Japan and Saudi Arabia due to some peculiar socio-cultural factors, demanding the proof of fertility after puberty and this encourages early marriages. ${ }^{[9]}$

Teenage pregnancies as seen in their study significantly are from single mothers with low level of education. This is similar to findings in the southern part of Nigeria. This ultimately results from low socio-economic status and ignorance on the important of antenatal care as well as poor support from the family. ${ }^{[6,9]}$ Some teen pregnant women may be abandoned or ostracized from the family cycle. This results in poor or no antenatal care and has been documented in similar studies on teenage pregnancy. ${ }^{[6]}$ Contrary to the above assertion some reports on good antenatal attendance among teenage pregnancies has also been documented in areas were early marriage is practiced..$^{[12]}$

The significant obstetric complications seen in this study include anemia in pregnancy, HIV infection, malaria in pregnancy, preterm delivery, postpartum hemorrhage and low birth weight. This obstetrics complication are similar to findings in other studies. ${ }^{[9,12-14]}$ Low birth weight, preterm deliveries and anemia in pregnancy has been reported to be due to significance influence of poor socio-economic conditions and possible high prevalence of medical illness like malaria in pregnancy. ${ }^{|6|}$ Pregnancy induced hypertension was not significantly associated with teenage pregnancy in this study though significant association had been noted 
in other studies. ${ }^{[12,15]}$ However, some studies have also reported no significant association with pregnancy induced hypertension which is similar to the findings in this study. ${ }^{[9]}$

Hypertension in pregnancy is postulated to be high among mature older women because essential hypertension and renal disease are common environmental findings with advancement of maternal age. ${ }^{\mid 6]}$ Furthermore in this study, teenage pregnancy was not significantly associated with threatened miscarriage, diabetes mellitus in pregnancy, intrauterine fetal death, premature rupture offetal membranes, uterine rupture, retained placenta, or twin gestation.

The cesarean section rate among teenage pregnancies was significantly high when compared with other control and this is similar to findings in other studies. ${ }^{[6,13,16]}$ Low cesarean section rate among teen pregnancies were reported in some studies. ${ }^{[14]}$ Most deliveries in this study were males. Birth asphyxia was a significant findings among teen delivered in this study and has been reported in other similar studies. ${ }^{[6]}$ This has been postulated to be due to fetal hypoxia, or distress which is linked to the poor socio-economic status, poor health seeking behaviors and lack of social/family support during pregnancy. The perinatal mortality in this study was also significantly high among teen mothers. This may be because teen mothers in this study were from poor socio-economic status with poor educational level and poor or low access to antenatal care. However, there have been reports of no significant difference in perinatal mortality in similar studies especially in areas where teen marriage is practiced and proper antenatal care as well as delivery are offered..$^{[9,12,14]}$

Teenage pregnancy in this study is associated with significant obstetric complications even though the incidence is low in comparison with similar hospital-based study in Nigeria. Teenage pregnancies were associated with a significantly higher risk of anemia in pregnancy, HIV in pregnancy, malaria in pregnancy, cesarean deliveries and poor fetal outcome.

\section{RECOMMENDATION}

There is need to increase the awareness on the problem associated with teenage pregnancy especially in areas that do not practice early marriage. Health education, women enlightenment and empowerment will also be essential in reducing the incidence and problem of teenage pregnancy. When teenage pregnancy occurs especially outside wedlock, effort should be made to support the teenager and enforce good antenatal and postnatal care. Sex education should be inculcated in the school curriculum of secondary education and parents should help in educating their children on issues of teenage pregnancy with emphasis on its possible complications. The unmet needs of contraceptive methods should be tackled especially as it affects the teenagers and effort should be made to make it available, affordable, accessible, feasible, sustainable and safe.

\section{REFERENCES}

1. Teenage pregnancy-Wikipedia the free encyclopaedia. Available from: http://www.en.wikipedia.org/wiki/teenage-pregnancy [Last accessed on 2011 Mar 05].

2. Fraser AM, Brockert JE, Ward RH. Association of young maternal age with adverse reproductive outcomes. N Engl J Med 1995;332:1113-7.

3. Nwobodo EI, Adoke KU. Obstetric outcome of teenage pregnancies at a tertiary care Hospital in Sokoto Nigeria. Trop J Obstet Gynaecol 2005;22:168-70.

4. Ogunniyi SO, Dare FO, Makinde OO, Nganwuchu AM. Obstetric performance of teenage pregnancies. Trop J Obstet Gynaecol 1991;9:38-9.

5. Akinola SE, Manne NC, Archibong EI, Sobande AA. Teenagers obstetric performance. Saudi Med J 2001;22:580-4.

6. Jimoh AS, Abdul IF. Outcome of teenage pregnancies in Ilorin, Nigeria. Trop J Obstet Gynaecol 2004;21:27-31.

7. Fakeye O. Body weight, and body component of total water, lean mass and fat at menarche. J Obstet Gynaecol 1990;8:22-4.

8. Kumar A, Singh T, Basu S, Pandey S, Bhargava V. Outcome of teenage pregnancy. Indian J Pediatr 2007;74:927-31.

9. Igwegbe AO, Udigwe GO. Teenage pregnancy: Still an obstetric risk. J Obstet Gynaecol 2001;21:478-81.

10. Loto OM, Ezechi OC, Kalu BK, Loto A, Ezechi L, Ogunniyi SO. Poor obstetric performance of teenagers: Is it age- or quality of care-related? J Obstet Gynaecol 2004;24:395-8.

11. Harrison KA. The influence of maternal age and parity on child bearing with special reference to primigravida aged 15 and under in child bearing health and social priorities. Br J Obstet Gynaecol 1985;suppl 15:23-31.

12. Mahfouz AA, el-Said MM, al-Erian RA, Hamid AM. Teenage pregnancy: Are teenagers a high risk group? Eur J Obstet Gynecol Reprod Biol 1995;59:17-20.

13. Adetoro OO, Agah A. The implications of childbearing in postpubertal girls in Sokoto, Nigeria. Int J Gynaecol Obstet 1988;27:73-7.

14. Omole-Ohonsi A, Attah RA. Obstetric outcome of teenage pregnancy in Kano, North-Western Nigeria. West Afr J Med 2010;29:318-22.

15. Aboyeji AP. Obstetric outcome of teenage primigravidae in Ilorin. Niger Med J 1997;31:56-9.

16. Verma $V$, Das KB. Teenage primigravidae: A comparative study. Indian J Public Health 1997;41:52-5.

How to cite this article: ${ }^{* * \star}$

Source of Support: Nil, Conflict of Interest: None declared 